\title{
HOMENAJE AL DR. SEIICHI IZUMI ${ }^{1}$
}

E Dr. Seiichi Izumi nació en 1915 en Tokio, como su padre era funcionario del Gobierno se trasladó a Corea juntamente con él. En Corea el Dr. Izumi estudió en la Universidad del Estado, primero Filosofía y después Antropología. En su vida de estudiante se interesó mucho en el estudio etnológico de Corea y comenzó a trabajar recogiendo materiales en el campo, aprovechando de sus vacaciones, y días feriados; perteneció, además al Club de Alpinismo en la Universidad donde estudiaba, dedicándose a escalar en los montes de Correa.

Cuando salió de la Universidad ya se había entusiasmado mucho por el estudio de la antropología. Después fue nombrado Asistente en la Universidad de Corea y comenzó a dedicarse al trabajo etnológico de campo en Manchuria, Mongolia y Asia Central. Durante la Segunda Guerra Mundial el Ministerio Naval de Japón envió al Dr. Izumi como miembro de la expedición promotora para indagar materia prima en Nueva Guinea, a su regreso al Japón presentó un trabajo sobre morfología de la tribus primitivas de Nueva Guinea; al mismo tiempo fue nombrado en otra Universidad, Catedrático Asistente.

Cuando hacía estudios en Mongolia para profundizar los trabajos antropológicos de campo, obligada por la guerra, la misión científica dirigida por el Dr. Izumi tuvo que regresar y como Japón perdió la guerra quedaron frustrados los sueños del Dr. Izumi para acabar los estudios antropológicos del continente asiático.

Concluida la Guerra Mundial, la Universidad de Tokyo, distinguió al Dr. Izumi. La UNES$\mathrm{CO}$ lo envió a Brasil para hacer trabajos sociológicos; desde entonces el profesor Izumi decidió dedicarse al continente americano. Desde los estudios sociológicos de la colonia japonesa en Brasil y Perú, bajo los auspicios del Ministerio de Relaciones Exteriores del Japón, se interesó mucho en la arqueología andina. En 1957 regresó al Japón desde Brasil, pasando por el Perú, donde hizo pequeños trabajos en el Valle de Chancay. En esta oportunidad, el Profesor Izumi, se puso en contacto con el Museo de Arqueología y Etnología del Universidad Nacional Mayor de San Marcos, haciéndose acompañar con los estudiantes Rosa Fung y Luis G. Lumbreras, que trabajaban en el Museo. En 1958 participó como Vice-Presidente de la Expedición Científica de la Universidad de Tokio e hizo estudio de las antiguas culturas peruanas, con la participación

1 Las informaciones bibliográficas del profesor Izumi han sido obtenidas de las Necrologías leídas por el señor Yasushi Miyazaki y el Director del Museo, en oportunidad del homenaje que el Museo hizo a su memoria el día miércoles 25 de noviembre de 1970. 
de varios estudiantes de arqueología de la Universidad de San Marcos; ese mismo año formó el Instituto Andino. En 1963, 1966 y 1969 volvió para terminar sus trabajos en las ruinas de Kotosh, iniciados en 1960.

Como miembro del Directorio de la Sociedad Etnológica del Japón y de la Asociación Promotora de Etnología japonesa, cumplió con todos sus proyectos, resolviendo sus problemas.

El año 1970 asumió la Dirección del Instituto de Cultura.

Justamente, una semana antes de que ocurriera su sensible fallecimiento, el doctor Seiichi Izumi asistía, como de costumbre, al Congreso Nacional de Antropología y Etnología. El 15 de noviembre de 1970 el mismo día de su muerte, planeaba la construcción de un Museo Antropológico de tipo mundial. 